Under dirty conditions, the economical load on a condenser should be about 5,300 B.Th.U. per sq. ft. for base-load stations, instead of the generally recommended figure of 7,000 . When the size of the turbine house building is fixed, it pays to install the largest condenser possible in the space available.

The relation between the normal vacuum in the condenser and the average temperature of the inlet circulating water has been practically fixed by convention. The sizes of condensers built in the United States are much the same as those built in Great Britain, but the quantity of water used is sometimes greater. Port Washington Power Station (U.S.A.) is the most efficient power station in the world. Monthly and yearly average operating figures are published from time to time. In 1937 the average load for the machines was nearly steady at 53,000 kilowatts. The greatest monthly average temperature rise of water, $4 \cdot 2^{\circ} \mathrm{F}$. above that of the circulating water inlet, occurred in March, and the smallest rise, $4.0^{\circ} \mathrm{F}$., occurred in August. The temperature rise of the circulating water of about $4 \cdot 0^{\circ} \mathrm{F}$. shows that the quantity of the circulating water is nearly 250 times the quantity of the steam condensed. It has to be noted that whatever the conventions adopted twenty years ago, prices and conditions have now considerably altered. The most important of these is the average loading of the plant, which, especially in base-load power stations, is considerably higher now than ever before. The cost of fuel per kilowatthour has not materially altered. The fuel consumption per unit has been reduced to a half during the last thirty years. This has been offset to a large extent by the rise in the price of coal, which is now double what it was. When river water is used for cooling, the temperature of the water is the theoretical lower temperature of the cycle; for cooling tower schemes it is the atmospheric wet bulb temperature. In a given locality, these two temperatures on the average are about the same: for example, about $52^{\circ} \mathrm{F}$. in Great Britain.

The approach of the condensing temperature to the theoretical temperature is limited by the question of cost, and the aim of the engineer is to design the plant so that the total annual cost including capital charges is a minimum. Mr. Bottomley shows mathematically that for conditions of minimum cost, the size of the condenser, the size of the tower and the quantity of circulating water can each be determined independently of the others, and this considerably simplifies the problem.

Among the important conclusions deduced is that the effect of deposit on the tubes can only be counteracted by increasing the tube surface and reducing the water velocity. No advantage is gained by increasing the quantity of the circulating water. Bearing in mind the cost of the circulating-water system and the cost of pumping, it is clear that the longer the circulating-water system is, the more the quantity of the circulating water should be reduced and the lower should be the normal vacuum in the condenser. Subject to the ground being suitable to bear the weight, power stations using tidal-river water cooling should be placed as near as possible to the river front, as this reduces the length and cost of the circulating-water system and also improves the overall efficiency of the station. By placing the station on the river front, a saving of about one per cent in the fuel consumption can be effected without reducing the distance between the intake and the discharge to the river, compared with a station placed about $800 \mathrm{ft}$. from the bank.

\title{
PLANNING IN GREAT BRITAIN
}

\begin{abstract}
A CONFERENCE on National Planning arranged by the Garden Cities and Town Planning Association was held at Oxford on March 28-30. An abstract of the valuable survey presented by Dr. Dudley Stamp at the Conference has already appeared in NATURE of May 24, p. 647. In what follows, digests are presented of some of the other contributions.

Mr. D. E. Gibson's paper on problems of decentralization, central development and satellite towns, while outlining the plans adopted by the Coventry City Council as a basis for Lord Reith's investigation, was essentially a discussion of some of these fundamental problems. It is obvious that we must have an idea of the size of the city for which we are planning before any intelligent planning is possible, and this is true whether of amenity services or of such problems as transport and roads. Such a question can only be answered when national planning arrangements have been made. National planning by the Government, as Mr. Gibson points out, is vital, because such information is required by all planning authorities in the country.

The valuable reports of the Barlow Commission and of PE P (Political and Economic Planning) do not supply all the material that is required as a basis for legislation, though the Conference re-directed attention to them, and Mr. H. W. J. Hick in particular, in his paper on "The Machinery of Planning",
\end{abstract}

urged the adoption of the findings of the Barlow Commission with the reservations and amendments of the signatories of the Minority Report. The field for further investigations, however, is admirably illustrated in some notes for discussion on planning principles by Mr. W. Harding Thompson, which formed one of the most valuable contributions to the Conference.

Mr. Thompson shows that while there may be general agreement as to the objectives of planning, and the argument for decentralization may be regarded as accepted as a basis of policy for the central planning authority, changes occurring during the War must be taken into consideration. Some war fastories may form the nuclei for new industrial settlements, but the central authority must at least provide a general outline plan on very broad lines for national zoning of industry. This plan, moreover, must take account of the balance of community life as well as of other economic and æsthetic factors. Planned redistribution is probably best applied to the numerous light and mobile industries with their wide choice of location.

The unit of regional planning also requires consideration in the light of experience of the civil defence regions. Mr. Thompson throws out as one suggestion the formation of industrial and agricultural planning boards, and stresses the necessity of harmonizing conflicting requirements of various 
Government Departments by the central or regional authority before transmission to local authorities, if local planning schemes are not to be delayed and confused. He reiterates with Mr. Gibson the importance of a local planning authority or joint committee deciding on the optimum size and population of a town before planning for increased industrial activity. Expansion beyond that size should be by means of arjjacent satellite or independent new communities within the region, each surrounded by a green belt.

The question of the optimum size of towns is one of the major problems on which further research is required. Obviously it may vary in accordance with physical limitations, the character and function of the town, the labour conditions, possible services, strategic situation and population required to support cultural activities, etc., and the analysis in the P E P report requires extension to some practical conclusion. The maximum density of development for urban areas, especially in residential units, is another matter in which further guidance is required, while the relation of agricultural to other industries established in rural districts needs investigation in several respects. The possibility of a further decrease of agricultural workers in Britain after the War, due to scientific and mechanized methods of farming and as a part of Imperial agricultural policy, must be seriously considered both in its effect on the vitality and mortality statistics and in relation to food policy and possible changes in production such as extended market gardening. Equally we have to consider the possibility of stabilizing and revitalizing rural community life by the introduction of selected light industries in villages, and the ways and means of safeguarding the benefits in health which have already flowed from the closer contact through evacuation of town workers with rural life.

Prof. J. H. Jones advocated the immediate establishment of regional boards, under the chairmanship of the Civil Defence Commissioners, to control the location of industry, and urged that the Government should decide whether the present Ministry of Works and Buildings is to be the effective Ministry of Reconstruction or to be superseded. Dr. Robson, in stressing the advantages of immediate planning to the war effort, holds that industry is capable of more control in its location than Prof. Jones suggested.

There can be no doubt that there are wide fields in which the planning of post-war Britain and the research and technique involved in reconstruction could be undertaken now with direct advantage to our war effort, apart altogether from the effect on public morale. There is much educational work to be undertaken, not merely of the general public, but also post-graduate education in such fields as organic planning, quantitative study of zoning areas, factorybuilding, shopbuilding, leasing and rent-fixing, control of use and design-aspects and techniques of town-building which, as Mr. F. J. Osborn pointed out, are not adequately covered in present townplanning education. There is also the vital contribution of the Building Research Station in regard to the use of new materials of construction as well as in matters of design, and here again research must be linked up with the development of new techniques and much far-reaching educational work.

\section{CRUSTAL STRUCTURE OF NEW ZEALAND}

\begin{abstract}
$\mathrm{K}$. E. BULLEN states that the progress of instrumental seismology has been slower in New Zealand than in a number of other earthquake regions, and it was not until the present decade that the identification of phases other than the normal $P$ and $S$ could be made in the records of near earthquakes (K. E. Bullen, "The Crustal Structure of the New Zealand Region as inferred from Studies of Earthquake Waves", Proc. Sixth Pacific Science Congress, 1939). The subsequent studies of the crustal structure of the New Zealand region have been subject to a number of special difficulties, of which some, but not all, have since been resolved or modified.

These difficulties centre chiefly around the considerable uncertainties in the determination of epicentres and origin times of many of the earthquakes which have shown phases in addition to $P_{n}$ and $S_{n}$. Epicentres are in general best determined from the absolute arrival times of $P_{n}$ at a sufficient number of stations, but until recently Wellington and Christchurch were the only stations the absolute time of which could be relied upon for such a purpose. This has necessitated recourse to $P_{n}-S_{n}$ intervals with the attendant difficulties of the accurate identification of the onset of $S_{n}$. There were doubts also concerning the normal $P$ velocity immediately below the crustal layers, and therefore by implication in the corresponding $S$ velocity also. A step forward was taken by Bullen when the significance of the phase $S^{*}$ was recognized in New Zealand earthquakes, following a study of the aftershocks of the Hawke's Bay earthquakes of February 2, 1931. It would appear that
\end{abstract}

$S^{*}$ has been recorded more often than any other phase in New Zealand and that $S^{*}$ may sometimes be recorded when the normal $S_{n}$ is completely missed. A revision of the analysis of the Wairoa earthquake of September 15, 1932, and of the Pahiatua earthquake of 1934 has led to further improvement. Statistical methods have been used wherever possible.

The new epicentre of the Wairoa earthquake was considered so satisfactory that new travel-time curves were prepared which, Bullen believes, approximate to the best results obtainable for the New Zealand region on the data so far available. The data refer particularly to that part of New Zealand which lies between latitudes $38 \cdot 5^{\circ} \mathrm{S}$. and $43 \cdot 5^{\circ} \mathrm{S}$. From these data $P^{n}$ up to $4^{\circ}$ has a velocity of $8 \cdot 1 \mathrm{~km}$. $/ \mathrm{sec}$. though the normal $7.8 \mathrm{~km}$. $/$ sec. fits nearer $6^{\circ}$. There are signs that $P^{*}$ is double with velocities 6.55 and $6.0 \mathrm{~km}$. $/ \mathrm{sec}$. $P_{\mathrm{s} \cdot 0}$ and $S_{3 \cdot 0}$ have additionally been recognized, the former making $S_{n}$ difficult to recognize at some stations. $P_{5 \cdot 0}$ has also been recognized by geophysical prospectors in New Zealand and may correspond to travel paths through greywacke, which occurs abundantly in the region between Wairoa and Wellington.

In conclusion, it is suggested by Bullen that the structure may be: (1) uppermost layer, perhaps a greywacke for a good part of the region, thickness $5-10 \mathrm{~km}$. with velocity of $P 5 \cdot 0 \mathrm{~km}$. $/ \mathrm{sec}$. and $S 3.0 \mathrm{~km} . / \mathrm{sec}$; (2) granitic layer, $4 \mathrm{~km}$. thick with velocity of $P 5 \cdot 5 \mathrm{~km} . / \mathrm{sec}$; (3) intermediate layers, $10-20 \mathrm{~km}$. thick altogether with velocities of $P 6 \cdot 0,6 \cdot 3,6 \cdot 5$ and $7 \cdot 0 \mathrm{~km}$./sec. and in the lower 